\title{
TAHSP:-
}

The Internet Joưnal of Allied Health Sciences and Practice

A Peer Reviewed Publication of the College of Health Care Sciences at Nova Southeastern University

Dedicated to allied health professional practice and education

http://ijahsp.nova.edu Vol. 12 No. 3 ISSN 1540-580X

\section{Integrated Clinical Experiences in a Campus Onsite Clinic: A Self-Contained Model of Physical Therapy Clinical Education}

\author{
Ann M. Wilson, PT, MEd, GCS \\ Clinical Associate Professor and Director of Clinical Education, Physical Therapy Program, University of Puget Sound, Tacoma, \\ Washington \\ United States
}

CITATION: Wilson A. Integrated Clinical Experiences in a Campus Onsite Clinic: A Self-Contained Model of Physical Therapy Clinical Education. The Internet Journal of Allied Health Sciences and Practice. July 2014. Volume 12 Number 3.

\begin{abstract}
Purpose: This paper describes a self-contained model of integrated clinical experiences (ICEs) that take place during the academic portion of an entry-level physical therapist education program in a campus onsite clinic. Description of Model: Students participate in ICEs for three consecutive semesters. Students provide pro bono physical therapy services to individuals with impairments, functional limitations, or changes in physical function resulting from a variety of health conditions. In addition, students participate in an exercise/wellness program for individuals who wish to improve or maintain their current levels of fitness. The first ICE consists of second-year students observing/assisting third-year students in the onsite clinic with basic patient care skills and participation in an exercise/wellness program. Students in the second and third ICEs provide ongoing oneon-one skilled therapy for individuals with neurological or musculoskeletal diagnoses. Results: Feedback obtained from onsite clinical instructors, core academic faculty, students, and patients receiving care in the onsite clinic through group debriefings, questionnaires, and interviews is used to assess students' readiness for full-time internships and effectiveness of the ICEs. The feedback reveals that the ICEs are meeting their intended goals. Category ratings in the "red flag" areas of the Clinical Performance Instrument (CPI) are consistently above expected levels for students completing their first full-time clinical internship. In addition, patients receiving care in the onsite clinic report a high level of satisfaction with the care provided. Conclusion/Possible Recommendations: This model provides students with an opportunity to gain clinical confidence in a realistic setting while reinforcing concepts presented in academic coursework. Providing ICEs on campus decreases reliance on clinical facilities and allows for academic program oversight of the quality of the learning experiences and early identification of students who have deficits in clinical skills and/or academic knowledge. The learning experiences provided in the onsite clinic give students a transitional experience that helps them benefit more fully from full-time internships. A potential challenge to this model is finding the space and financial resources needed to make it viable.
\end{abstract}

\section{INTRODUCTION AND PURPOSE}

Clinical education is crucial to the development of competent entry-level physical therapists. Therefore, a significant portion of entry-level physical therapist education is devoted to clinical education. Clinical education accounts for approximately one-third of the curriculum in accredited physical therapist education programs. ${ }^{1}$ The number of clock hours spent in full-time clinical education ranges from 920 to 2,160 hours with a mean of 1,431 hours, while the number of clock hours spent in part-time clinical experiences ranges from 0 to 1,624 hours with a mean of 103 hours. $^{2}$

Integrated clinical experiences (ICEs), also referred to as first-level clinical education experiences, clinical practicums, clerkships, or part-time clinical experiences provide students with an opportunity to integrate academic knowledge and skills with practical experience while concurrently completing coursework in the academic program. ICEs focus on the foundation of clinical practice and the development of professional behaviors. A qualitative study by Weatherbee et al revealed that $\mathrm{Cls}$ and new graduates 
agree that ICEs are an important part of students' academic preparation prior to full-time clinical internships. ${ }^{3}$ The majority of physical therapist education programs provide some type of ICE as part of their curriculum. ${ }^{2}$

The Commission on Accreditation of Physical Therapy Education (CAPTE) gives programs considerable latitude in configuring integrated or part-time clinical experiences or in a way that fits their particular curricular model. ${ }^{1}$ The guiding documents that education programs use to develop curriculum such as the Evaluative Criteria for Accreditation of Education Programs for the Preparation of Physical Therapists and A Normative Model of Physical Therapist Professional Education: Version 2004 do not specify the length or number of part-time clinical experiences or the settings in which those experiences should take place.1,3,4

Several issues are having an impact on physical therapy clinical education. First, the increasing student population as a result of the number of new and developing physical therapist and physical therapist assistant education programs is making it challenging to find enough placements for clinical internships and part-time clinical experiences in particular. Recent changes in reimbursement and stricter regulations related to student supervision have also had an impact..$^{5-6}$ In addition, the changing health care environment is placing greater demands on clinicians for productivity, which is having an impact on the number of clinical sites that are willing to provide clinical education, particularly part-time experiences. ${ }^{7-9} \mathrm{In}$ light of these issues, physical therapist education programs should consider alternative ways to provide high-quality clinical education experiences for their students. ${ }^{7-9}$

One way to address the shortage of clinical sites willing or able to take students is for education programs to provide ICEs as part of the academic curriculum. In response to this need, a number of ICE or part-time clinical education models have been described.7,8,10,11 For example, Scherer et al described early clinical education experiences consisting of clinical education courses concurrent with the academic program that take place one day per week for seven weeks in the first year of the program and one day per week for 14 weeks in the second year of the program. ${ }^{7}$ These experiences took place in local acute care, neurorehabilitation, or outpatient musculoskeletal clinics. Supervision and clinical mentoring were provided using a collaborative model with a student-to-Cl ratio of 2:1. Cls were employees of the facilities in which students were placed for the experiences. Students in the first course performed routine skills typically assigned to physical therapy aides as well as basic clinical skills and examination procedures commensurate with the students' academic preparation in those areas. Students also had opportunities to perform examinations, evaluations, and intervention planning for individuals with musculoskeletal diagnoses on a limited basis in the second year of the program.

Stern and Rone-Adams described a first-level clinical education model in which first and second-year students rotated through different types of clinical settings in the community to practice routine patient care skills concurrent with coursework they were completing in the academic program. ${ }^{8}$ Students were in the clinical settings one day every other week for three consecutive semesters. Core faculty served as $\mathrm{Cls}$ for the experiences using a collaborative model with a student-to-Cl ratio of 8:1. Stern and Rone-Adams' model also included a peer mentoring component in which first-year and second-year students worked collaboratively in pairs. Specific learning objectives were identified in the cognitive, psycho-motor and affective domains for each experience. $^{8}$

Similarly, Weddle and Sellheim described a model of integrated clinical education in which the university collaborated with several local health care facilities to provide integrated clinical education experiences for first and second-year physical therapy students. ${ }^{10}$ Students were involved in the clinic for approximately 75 hours in the first year and 18 hours in the second year. Although the integrated clinical education experiences spanned two years of the program, the model description focused primarily on the first-year experience. Clinical instruction was provided by clinical faculty members who designed learning activities to coincide with or complement academic instruction. The clinical faculty who provided instruction for these experiences were therapists employed by the facilities that had agreed to serve as clinical sites for the experience, and the university reimbursed the clinical sites for the clinical faculty time..$^{10}$

Most recently, Mai et al described a comprehensive ICE model that consisted of three courses offered in consecutive semesters of an academic program. ${ }^{11}$ The ICE courses meet for 2 hours twice a week in clinical facilities both on and off campus. Supervision was provided by core faculty members using a collaborative model with a student-to-Cl ratio of 7-8:1. Students in the first ICE course participated in a community-based wellness program and provided exercise prescription and instruction for two to four clients weekly. Students in the second ICE course provided one-on-one care for patients/clients practicing musculoskeletal and neuromuscular examination, evaluation and intervention skills on a limited basis. Students in the third ICE course practiced mentoring and supervisory skills by serving as peer mentors for students in the first ICE course. ${ }^{11}$

Although these models differ somewhat in their approaches to providing part-time clinical experiences, all are designed to enhance or reinforce academic knowledge and improve student readiness for full-time clinical internships. Each of the models

(c) The Internet Journal of Allied Health Sciences and Practice, 2014 
described above relies on the local therapy community for clinic space, access to patient populations, or personnel to provide clinical instruction. The logistics involved with establishing partnerships with clinical facilities, recruiting patients/clients, and identifying therapists who can mentor students for these experiences can be daunting for program faculty and administrators. Finding ways to address these issues is an important consideration for physical therapist education programs, especially those in small liberal arts colleges that are not directly affiliated with large medical centers. Therefore, the purpose of this paper is to describe one entry-level physical therapist education program's experience with providing self-contained integrated clinical experiences in a campus onsite clinic.

\section{METHODS}

The clinical education component of the Doctor of Physical Therapy (DPT) program at the University of Puget Sound, a small liberal arts college in the Pacific Northwest, consists of three 12-week, full-time clinical internships and ICE courses that take place in a campus onsite clinic during the second and third years of the academic program. Table 1 outlines the program sequence and the placement of each of the ICE courses within the curriculum. These experiences, which increase in complexity each semester, coincide with the progression of courses in the academic program and provide students with opportunities to experience all aspects of patient management in a realistic setting.

\begin{tabular}{|l|} 
Table 1. Curricular Sequence \\
\begin{tabular}{|l|l|}
\hline \multicolumn{2}{|c|}{ Year 1 } \\
\hline Fall Semester & Spring Semester \\
\hline Basic Skills I & Basic Skills II \\
\hline Functional Anatomy \& Biomechanics & Neuroscience and Neuroanatomy \\
\hline Introduction to Critical Inquiry & Ambulatory Function \\
\hline Introduction to Professional Issues & Physical Agents and Electrotherapy \\
\hline Principles of Cardiopulmonary PT & \\
\hline
\end{tabular}
\end{tabular}

\begin{tabular}{|l|l|}
\hline \multicolumn{2}{|c|}{ Year 2 } \\
\hline Fall Semester & Spring Semester \\
\hline Basic Skills I & Basic Skills II \\
\hline Functional Anatomy \& Biomechanics & Neuroscience and Neuroanatomy \\
\hline Introduction to Critical Inquiry & Ambulatory Function \\
\hline Introduction to Professional Issues & Physical Agents and Electrotherapy \\
\hline Principles of Cardiopulmonary PT & \\
\hline
\end{tabular}

Summer

PT 657 Clinical Internship I

\begin{tabular}{|l|l|}
\hline \multicolumn{2}{|c|}{ Year 3} \\
\hline Fall Semester & Spring Semester \\
\hline Geriatrics & Clinical Internship II \\
\hline Integrated Clinical Experience III & Clinical Internship III (spans spring and summer) \\
\hline Psychological Factors in PT Practice & \\
\hline Clinical Research & \\
\hline PT Administration & \\
\hline Two Advanced Electives in PT & \\
\hline
\end{tabular}

The onsite clinic serves members of the campus community as well as individuals from the local area who may not otherwise have access to physical therapy care for financial reasons. Patients/clients can gain access the clinic either by self-referral or by referral from a local health care provider. PTs and health care providers in the community often refer individuals whose insurance benefits have expired or those who have limited coverage and are in need of further skilled care.

Students provide one-on-one physical therapy services to individuals with impairments, functional limitations, or changes in physical function resulting from a variety of musculoskeletal, neurologic, or systemic health conditions. In addition, the onsite clinic offers a separate exercise/wellness program for individuals who wish to improve or maintain their current levels of fitness. The physical therapy services are provided at no cost; however, there is a nominal administrative support fee which is used to 
purchase expendable supplies. The clinic operates as a pro bono service to the community; thus, no one is turned away due to an inability to pay the support fee.

Because the ICEs are part of the academic curriculum, the university fully funds and supports the operation of the campus onsite clinic. The university provides clinic space and equipment, administrative support, compensation for Cls, and liability insurance coverage for both students and Cls. The onsite clinic is a 6,370 square-foot facility located in a state-of-the-art campus building that houses the School of Occupational Therapy and Physical Therapy. The clinical facility features separate treatment areas for adults and pediatrics, a gym that houses larger exercise and mobility equipment, an apartment lab, and a community mobility park. The onsite clinic space is used for laboratory sections of clinically-oriented academic courses on non-clinic days.

Clinical instruction for the ICEs is provided by a combination of core faculty and physical therapy clinicians from the local community who are hired by the university to serve as Cls. Requirements to serve as a $\mathrm{Cl}$ in the onsite clinic include a minimum of three years of current or recent full-time clinical experience and completion of the American Physical Therapy Association's Credentialed Clinical Instructor Program (CCIP). The onsite clinic uses the collaborative model of clinical education with a student-to- $\mathrm{Cl}$ ratio that ranges from 2:1 in the spring semester to $4: 1$ in the fall semester, depending on the student's level in the program. The exercise/wellness group has a student-to-Cl ratio of 8:1.

Table 2. Outcomes for Integraded Clinical Experiences

\begin{tabular}{|c|c|}
\hline Integrated Clinical Experience & Outcomes \\
\hline ICE I & $\begin{array}{ll}\text { - } & \text { Become familiar with clinic environment } \\
\text { - } & \text { Observe and assist with patient care } \\
\text { - } & \text { Practice documentation and interviewing skills } \\
\text { - } & \text { Prescribe exercise for a healthy population }\end{array}$ \\
\hline ICE II & $\begin{array}{ll}\text { - } & \text { Develop patient-professional interaction skills } \\
\text { - } & \text { Develop documentation skills } \\
\text { - } & \text { Develop skill in patient handling and treatment } \\
\text { interventions } \\
\text { Develop critical clinical reasoning and clinical } \\
\text { decision-making skills }\end{array}$ \\
\hline ICE III & $\begin{array}{ll}\text { - } & \text { Refine patient-professional interaction skills } \\
\text { - } & \text { Assume responsibility for all aspects of patient } \\
\text { - } & \text { Refine documentation skills } \\
\text { - } & \text { Refine clinical reasoning and clinical decision- } \\
\text { - } & \text { making skills } \\
\text { Begin to develop peer mentoring and supervisory } \\
\text { skills }\end{array}$ \\
\hline
\end{tabular}

\section{Integrated Clinical Experience I}

The ICE courses begin in the fall semester of the second year of the program. Students spend one day per week shadowing and assisting third-year students in the provision of patient care and participating in an exercise/wellness group. Over the course of the semester, students work with third-year student therapists who are treating adult or pediatric patients/clients with musculoskeletal and neurological diagnoses. Although the experience includes observation of patient treatment, second-year students are actively engaged in the provision of care on a limited basis. Participation in patient care includes tasks such as taking vital signs, measuring joint range of motion, applying physical agents, supervising exercise programs, or assisting with functional activities. These skills, which were taught in the first year of the program, are reviewed in a lab classroom setting prior to beginning patient care. Third-year peer mentors and their clinical instructors provide feedback to the second-year students and Cls about the second-year students' performance of assigned clinical tasks. Second-year students also practice taking patient histories and writing progress notes for each of the therapy sessions in which they are involved. The practice documentation is reviewed by peer mentors, and Cls and the students receive feedback on the content and quality.

In addition to assisting third-year students with routine patient care skills, second-year students also participate in an exercise/wellness group, which is a separate component of the onsite clinic. The exercise/wellness group is intended for individuals who wish to begin or modify an existing personalized exercise program. Students, working in pairs, design a personalized exercise program for a client that addresses elements of strength, endurance, and/or flexibility. The exercise/wellness group meets once a week for six weeks. The goal is to provide clients with a community-based or home exercise program that can be continued independently once the program ends. Exercise/wellness group clients agree to stay for 
30 minutes after the end of each scheduled exercise session to allow second-year students additional time to practice routine tests and measures such as manual muscle testing, joint range of motion measurement, and taking vital signs in a clinical setting.

Licensed PTs mentor and supervise the exercise prescription and instruction in a group setting with a student-to-Cl ratio of 8:1, which is the same ratio described by Stern and Rone-Adams and Mai et al.8,11 The student-to-Cl ratio is appropriate for the exercise/wellness group because students work in pairs with a total of four exercise group clients at a time. The physical configuration of the clinic allows for line-of-sight supervision of all students by the Cls. Students discuss exercise plans and the progress of their exercise/wellness clients in weekly planning and debriefing meetings with their Cls that take place prior to and following each exercise/wellness group sessions.

Second-year students also attend third-year student-Cl cohort meetings either prior to or following each of the treatment sessions they observe. In addition, the ICE has a companion clinical seminar that meets weekly in which students discuss issues related to the clinic shadowing experiences with the Director of Clinical Education (DCE) who is the faculty member responsible for the clinical seminar. Second-year students also meet weekly with their third-year peer mentors to discuss progress and goals for the upcoming week.

Grading for this ICE is based on written evaluations of student performance from both peer mentors in the onsite clinic and from Cls in the exercise/wellness group. A sample of the summative student evaluation form used for this experience can be seen in Appendix A. Students are evaluated in the areas of safety, professional behavior, communication skills, documentation and evidence of emerging clinical skill acquisition.

The expected outcomes for ICE I are listed in Table 2. The primary outcome for the first ICE is to help students become familiar with the clinic environment. Students begin to develop professional communication skills with patients, peers, and clinical instructors. In addition, students have an opportunity to practice basic patient care skills in a realistic setting and to develop an exercise prescription for individuals without significant impairments or functional limitations.

\section{Integrated Clinical Experience II}

Students are in the onsite clinic a half day one day per week for 15 weeks in the spring semester of the second year. The patient population consists of adults with musculoskeletal or neuromuscular diagnoses. Students assume responsibility for the provision of one-on-one patient care under the supervision and guidance of a licensed PT Cl. The student-to-Cl ratio for this experience is 2:1. Because these students have not yet completed all clinically-oriented didactic coursework, the $\mathrm{Cl}$ performs the initial examinations while the students observe and assist. The student and $\mathrm{Cl}$ work together to establish the initial plan of care and goals. The student then assumes responsibility for the ongoing care including evaluation, intervention planning and implementation, re-assessment, discharge planning, and referral to and communication with health care providers. Patients/clients are seen for one-hour appointments, and each student has a caseload of three patients. Student pairs meet with their $\mathrm{Cl}$ prior to and following each clinic session. The purpose of these meetings is to discuss daily treatment plans, problemsolve, and debrief how the sessions went. Cls also use this time to discuss treatment efficiency and skill refinement.

Grading for this ICE is based on written midterm and evaluations of the Cl's assessment of the student's performance in the areas of safety, professional behavior, communication, examination and intervention skills, and clinical reasoning. A sample of the summative student evaluation form for this experience can be seen in Appendix B. The expected outcomes for ICE II are listed in Table 2. The primary outcomes for this experience are for the student to become comfortable interacting with patients and $\mathrm{Cls}$, to begin to develop skill in handling patients during examination, and to develop skill in applying treatment interventions. In addition, students begin to develop documentation, problem-solving, and clinical decision-making skills.

\section{Integrated Clinical Experience III}

Students complete the first of three 12-week full-time clinical internships in the summer between the second and third academic years and return to the onsite clinic in the fall semester of the third year for a final ICE course. The patient population for ICE III is comprised of adults with musculoskeletal or neuromuscular diagnoses as well as pediatrics with musculoskeletal, developmental, or neuromuscular diagnoses. Third-year students are in the clinic two half days per week and are responsible for providing oneon-one physical therapy services under the supervision of a licensed PT Cl. This experience uses a collaborative model with a student-to- $\mathrm{Cl}$ ratio of $4: 1$. The primary role of the $\mathrm{Cl}$ is to facilitate clinical discussions and challenge the students' ability to articulate the rationale behind their clinical decisions. This experience also complements the second-year ICE in that the students in the third year of the program serve as peer mentors to second-year students who assist with treatments. 
Patients/clients are seen for one-hour appointments twice a week. Each student has a caseload of three patients per day. Students are responsible for all aspects of patient management including examination, intervention planning and implementation, documentation, discharge planning, and referral to and communication with other health care providers. The expected outcomes for ICE III are listed in Table 2.

Student cohorts meet with their Cls prior to and following each clinic session. The purpose of these meetings is to discuss daily treatment plans, problem-solve, and debrief how the sessions went. Cls sometimes use this time to consult with students regarding skill refinement, suggest alternative interventions, or pose clinical controversies that the cohort can discuss as a group. Students are expected to present evidence for the interventions provided to their cohort group and to identify relevant outcome measures for the individuals they are treating. Grading for this ICE is based on written midterm and final evaluations of the Cls assessment of the student's performance in the areas of safety, professional behavior, communication, examination and intervention skills, and clinical reasoning. A sample of the summative student evaluation form for this experience can be seen in Appendix C. The outcomes for this experience are for the student to develop clinical decision-making skills including critical thinking, clinical reasoning and clinical judgment, demonstrate safe and efficacious clinical practice, and participate effectively as a team member in a collaborative environment.

\section{RESULTS/OUTCOME}

A group debriefing with all Cls and all students takes place at the end of each ICE to assess the overall experience. Students and Cls meet together in groups of six to seven to discuss issues such as advantages and challenges of using the collaborative model in this setting and the challenges and rewards of the overall experience. In addition, students and $\mathrm{Cls}$ are given an opportunity to make recommendations for future iterations of the clinic experience and to share ideas regarding improvements in general clinic operation, etc. The responses to open-ended questions about these issues are recorded by each group and returned to the DCE for collation. The collated responses to these questions are shared with the core faculty and clinic Cls. Information from these debriefing responses is used to inform changes in clinic operation, clinical supervision, etc. An example of the collated responses from small groups following the ICEs in fall 2012 can be seen in Appendix D.

Students in ICE II and ICE III (second and third-year students together) participate in a separate group debriefing about the peer mentoring component of the experience. Mixed small groups of second and third-year students discuss and record responses to open-ended questions about the challenges and rewards of the peer mentoring component of the ICE. The recorded responses are returned to the DCE for collation at the end of the discussion. The collated responses to these questions are shared with the entire third-year class as well as the clinical faculty. An example of the collated responses from the group debriefing in fall 2012 can be seen in Appendix E.

Cls from the onsite clinic meet with core academic faculty at the end of each semester in an advisory capacity to discuss the integration of academic work into the clinical environment. The purpose of these meetings is to provide core faculty with information regarding individual student readiness for full-time clinical internships and to identify areas in which the curriculum may better facilitate the students' transition from academic program to clinical education. Feedback received from clinic $\mathrm{Cls}$ has resulted in a number of positive changes within the academic curriculum that have enhanced students' professional and clinical development. The Cls who are not core faculty gain a deeper understanding of the developmental nature of the curriculum and how to best support student development in light of that.

During full-time clinical internships, Cls and Center Coordinators of Clinical Education (CCCEs) are invited to share their perceptions of the program and student preparation during clinical site visits conducted by the DCE and core faculty. Anecdotal evidence collected from those clinical site visits suggests that Cls and CCCEs recognize and appreciate the vital role that the onsite clinic plays in student development and clinical readiness. Similarly, students interviewed during clinical site visits are specifically asked about the ways in which the onsite clinic contributed to their professional development. Students consistently report that their experience in the onsite clinic improved their professional confidence and enhanced their preparation for full-time clinical internships. Students continue to value the ICEs in the onsite clinic even after graduation. Open-ended comments from program graduates on graduate surveys conducted at one year, three years, and five years post-graduation indicate that the onsite clinic provided a solid foundation on which to build confidence and professional development.

In addition to providing a unique learning opportunity for students, the onsite clinic also provides a significant benefit to the community. In fact, the onsite clinic and exercise/wellness group had over 2,700 patient/client visits during the 2012-2013 academic year. Patient satisfaction questionnaires are distributed at the end of each episode of care. The questionnaire (see Appendix F), adapted from one published in The Guide to Physical Therapist Practice $2^{\text {nd }} \mathrm{Ed}$., is provided to patients/clients via SurveyMonkey ${ }^{\mathrm{TM}}$ or in hard copy to those individuals without computer access. Questionnaire response rates vary from

(c) The Internet Journal of Allied Health Sciences and Practice, 2014 
semester to semester with an average response rate of 36 percent that has remained relatively consistent each year since 2010. Aggregate data from questionnaires collected since 2010 suggests that individuals are highly satisfied with the care they receive in the campus onsite clinic. For example, respondents are asked to rate the degree of satisfaction with the care they received in the onsite clinic in a variety of areas on a Likert-type scale of 1-5 where " 1 " = strongly disagree and " 5 " = strongly agree. Ninetythree percent of respondents rated their satisfaction with the treatment provided by their student therapist at either a " 4 " (14\%) or a "5" (86\%). Similarly, 80 percent of respondents rated their satisfaction with the overall clinic experience a " 5 " while the remaining $20 \%$ rated the experience at a " 4 ". Respondents are also invited to make comments about their experience in the onsite clinic. Representative examples of comments on questionnaires collected between 2010 and 2012 include statements such as:

"My experience was great! So much different than what I have experienced in the 'real' world."

"I have had PT before but this was more comprehensive and thorough any other time I have ever had therapy."

"I had heard over the years that you had a good program. After my experience, I can agree that the program is excellent!"

"I am so grateful for the care that I received in the clinic. The compassion and professionalism of everyone was evident. Thank you for providing this service."

"I have noticed a remarkable improvement in my husband's ability to walk both inside and outside of our home since he started coming to the clinic. We are grateful for having had the opportunity to participate."

Student performance in key areas of the Physical Therapist Clinical Performance Instrument (PT CPI) suggests that students who successfully complete the first two ICE courses perform particularly well in the performance criteria identified as "red-flag" areas upon completion of the first full-time internship. The "red-flag" items on the PT CPI that are considered fundamental to clinical practice include Safety, Professional Behavior, Accountability, Communication, and Clinical Reasoning. ${ }^{16}$ Aggregate data from the rating scales attached to each of these areas was between "Advanced Intermediate" and "Entry-Level" at the end of the first full-time clinical internship for all students in 2011 and 2012. It is difficult to determine whether that performance is solely a result of the students' experience in the onsite clinic; however, it is reasonable to assume that the experience helps students become proficient in these areas earlier than students who do not have such experiences.

\section{DISCUSSION/CONCLUSION}

ICEs are integral to preparing students for clinical internships, and a variety of models have been used to create such experiences.7,8,10,11 The ICE model described in this paper is similar in many respects to those reviewed. For example, each model has the overarching goal of integrating didactic course content with clinical skill acquisition and promoting professional behaviors in a realistic setting. ${ }^{7-8,} 10-11$ Although the experiences differ in length and scope, each is designed to coincide with student progression through the academic program. $7,8,10,11$ This ICE model as well as the others described in this paper utilize the collaborative model of clinical education with student-to- $\mathrm{Cl}$ ratios of 2:1, 4:1, or 8:1.7,8,10,11 The practicality and viability of the collaborative model in clinical education have been demonstrated to be successful for teaching and learning in a variety of clinical settings. ${ }^{12-15}$ There are several additional benefits of using the collaborative model in this setting. These include peer support, the development of self-reliance, and teamwork skills. ${ }^{13}$ In addition, the collaborative model is more cost-effective and practical for the university than the traditional 1:1 model of clinical education. ${ }^{13}$

Peer mentoring is a component of two of the models reviewed as well as the model described in this paper. 8,11 Peer mentoring provides more experienced students with realistic exposure to some of the issues they will face as $\mathrm{Cls}$ in the future. For example, the peer mentors begin to develop skill in providing formative and summative feedback and determining when clinical skills can be assigned to more novice students. In addition, peer mentoring reinforces the mentor's own knowledge base as well as the ability to convey that knowledge to others. ${ }^{11}$ Furthermore, peer mentoring can be used as one way to demonstrate compliance with CAPTE's Evaluative Criteria for Accreditation of Education Programs for the Preparation of Physical Therapists 1 in the area of Professional Practice Expectation: Professional Duty by providing students with an opportunity to participate in peer assessment and clinical teaching.

The present model as well as those described by Stern and Rone-Adams and Mai et al, respectively engage students in service learning by providing pro bono physical therapy services.8,11 The pro bono care provided in this and other models embody the spirit of altruism identified as one of the American Physical Therapy Association's Core Values and model that realm of professionalism for the students. ${ }^{18}$

The most significant differences between this model and others are the location in which the experiences take place, the scope of care provided, and the fact that clinical supervision is provided by a combination of core faculty and therapists from the community. This ICE model takes place in a campus onsite clinic designed specifically for that purpose. There are several

(c) The Internet Journal of Allied Health Sciences and Practice, 2014 
advantages to having a clinic located on campus. An on-campus location eliminates the challenge of finding clinical sites willing to provide part-time clinical education experiences. The campus location allows for better academic program oversight of the learning experiences and more direct involvement of the core faculty. Because the clinic is not part of another clinic or health care facility, students are responsible for aspects of clinic operation other than providing patient care. The campus onsite clinic visibly connects the academic and clinical components of the education program to both the university community and the community at large. Finally, the clinic's presence on a university campus helps students realize that clinical education is a continuation of the academic preparation rather than a separate entity.

The scope of this ICE model is significantly more clinically-oriented that of other models because of the amount of independent, one-on-one care provided. Students in the ICE II and ICE III courses are responsible for managing a caseload of patients throughout an entire episode of care. This allows them to develop skill in all aspects of patient management from initial examination to discharge. Having responsibility for managing a small caseload provides an opportunity for students to begin to develop skills in time management and treatment efficiency early in their clinical education.

The collaborative model of clinical education used in this model varies according to the level of student involvement in providing one-on-one care. Direct clinical instruction for the experiences is provided by core faculty and supplemented by therapists who are hired to serve as Cls. The advantage of having core faculty provide clinical instruction for these experiences is that it allows them to evaluate the effectiveness and carryover of course content by observing student performance in a realistic setting and to identify students who have deficits in clinical skills and/or academic knowledge.

While there are several benefits of providing ICEs in a campus clinic, there are also some barriers. The most significant barriers are securing the physical space to house a clinic on campus and garnering the financial resources needed to operate the clinic. University administrations may be willing to provide these resources once they realize the positive impact that an onsite clinic can have on the program and the community. Other barriers may include building clinical instruction into core faculty teaching loads and finding qualified community therapists who are willing to work in the clinic on a part-time basis. Finally, building community support for a clinic that is located in close proximity to outpatient clinics can be challenging due to concerns about interfering with the revenue stream of the for-profit clinics. If an education program has a good working relationship with area clinics, this barrier can be eliminated, particularly if the onsite clinic is providing only pro bono care.

In conclusion, this paper has described a model for providing ICEs in a self-contained onsite clinic designed specifically for that purpose. The guided practice and close mentoring in the onsite clinic provide students with an opportunity to gain clinical confidence in a realistic setting while reinforcing concepts presented in academic coursework. The learning experiences provided in the onsite clinic give students a transitional experience that helps them benefit more fully from full-time internships.

\section{REFERENCES}

1. Commission on Accreditation in Physical Therapy Education. CAPTE Accreditation Handbook: Evaluative Criteria for Accreditation of Education Programs for the Preparation of Physical Therapists. Alexandria, VA: American Physical Therapy Association; 2013.

2. Commission on Accreditation in Physical Therapy Education 2011-2012 Fact Sheet: Physical Therapist Education Programs. http://www.capteonline.org/uploadedFiles/CAPTEorg/About_CAPTE/Resources/Aggregate_Program_Data/AggregateProgr amData_PTPrograms.pdf. Accessed February 4, 2013.

3. Weatherbee E, Peatman N, Kenney D, Cusson M, Applebaum D. Standards for clinical education: A qualitative study. J Phys Ther Educ. 2010;24(3):35-43.

4. American Physical Therapy Association. A Normative Model of Physical Therapist Professional Education: Version 2004. Alexandria, VA: American Physical Therapy Association; 2004.

5. Federation of State Boards of Physical Therapy.Ingram D, Roesch R. Physical Therapist Clinical Education Models Overview. Federation Forum 2012._https://www.fsbpt.org/download/Forum_Summer2012_ClinicalEducationModel.pdf. Accessed February 4, 2013.

6. Dunfee HJ. Clinical education: Past, present and future. J Phys Ther Educ. 2008; 22(3):3-5.

7. Scherer CL, Morris DM, Graham C, White LW. Competency-based early clinical education experiences for physical therapy students. The Internet Journal of Allied Health Sciences and Practice. Apr 2006:4(2) http:/lijahsp.nova.edu. ISSN 1540580X. Accessed February 9, 2013.

8. Stern D, Rone-Adams S. An alternative model for first-level clinical education experiences in physical therapy. The Internet Journal of Allied Health Sciences and Practice. July 2006:4(3) http://ijahsp.nova.edu. ISSN 1540-580X. Accessed February 9, 2013. 
9. American Physical Therapy Association. Clinical Education Principles.

http://www.apta.org/uploadedFiles/APTAorg/Educators/Clinical_Development/Education_Resources/PTClinicalEducationPri nciples.pdf. Accessed February 9, 2013.

10. Weddle ML, Sellheim DO. Linking the classroom and clinic: A model of integrated clinical education for first year physical therapist students. J Phys Ther Educ. 2011;25(3):68-79.

11. Mai JA, Thiele A, O'Dell B, Kruse B, Vaassen M, Priest A. Utilization of an integrated clinical experience in a physical therapist education program. J Physical Ther Educ. 2013;27(2):25-32.

12. DeClute J, Ladyshewsky R. Enhancing clinical competence using a collaborative clinical education model. Phys Ther. 1993;73:683-9.

13. Ladyshewsky R. Clinical teaching and the 2:1 student-to-clinical instructor ratio. J Phys Ther Educ. 1993; 76(9):31-5.

14. Rindflesch AB, Dunfee HJ, Cieslak KR, Eischen SL, Trenary T, Calley DQ, Heinle DK. Collaborative model of clinical education in physical and occupational therapy at the Mayo Clinic. J Allied Health. 2009;38(3):132-42. [PMID 19753424]

15. Ladyshewsky RK, Barrie SC, Drake VM. A comparison of productivity and learning outcome in individual physical therapy clinical education models. Phys Ther. 1998;78:1288-301.

16. American Physical Therapy Association. APTA Physical Therapist Clinical Performance Instrument for Students: A SelfGuided Training Course.

http://learningcenter.apta.org/shared/courseDescription.aspx?courselD=1289\&client|D=501\&URL=http://learningcenter.apta .org. Accessed March 2, 2013.

17. American Physical Therapy Association. A Guide to Physical Therapist Practice. $2^{\text {nd }}$ Ed. Alexandria, VA: American Physical Therapy Association; 2003.

18. American Physical Therapy Association. Professionalism in Physical Therapy: Core Values. http://www.apta.org/documents/public/education/professionalism.pdf. Accessed February 24, 2013. 


\section{APPENDIX A}

\section{ICE I Student Performance Evaluation}

The outcomes for this experience are for the student to begin to:

- develop comfort interacting and communicating with patients, Cls and peers in a professional environment.

- develop skill in performing routine tests and measures such as vital signs, joint range of motion or muscle length testing or manual muscle testing.

- develop skill in prescribing exercise for a healthy population, both in a clinical setting and with a home exercise program.

- develop documentation skills that include appropriate content and terminology and a concise and specific assessment.

- gain insight into their own clinical strengths and areas where they need support.

In light of the outcomes above, please summarize the student's current status in each of the following categories. In each instance, highlight an area of skill or strength and an area to focus for development.

EXAMINATION/EVALUATION: (i.e., ability to perform appropriate intake exam for exercise clients and skill level in performing basic tests and measures.)

Strength

Focus for development

TREATMENT/INTERVENTION: (i.e., preparation for treatment, responsiveness to patient performance, development of an appropriate exercise program that addresses elements of strength, flexibility and endurance and considers client goals.)

Strength

Focus for development

DOCUMENTATION: (i.e., clarity, amount of feedback for documentation, appropriate terminology, timeliness, etc.)

Strength

Focus for development

COMMUNICATION: (i.e., communication with patients, family, Cls, peer mentors and classmates.)

Strength

Focus for development

SAFETY: (i.e., awareness of surroundings, appropriate precautions, recognizing physiologic status of patient, guarding techniques and personal body mechanics.)

Strength

Focus for development

PROFESSIONAL BEHAVIORS: (i.e., personal appearance, punctuality, preparation, awareness of personal characteristics, behaviors during clinic and ability to take and give feedback.)

Strength

Focus for development

OVERALL IMPRESSION OF STUDENT'S PERFORMANCE:

(c) The Internet Journal of Allied Health Sciences and Practice, 2014 


\section{APPENDIX B}

ICE II Student Performance Evaluation

The intended outcomes for this experience are for the student to:

- have a "picture" of what they hope to be able to do independently when evaluating a new patient.

- understand the concepts of rationale for treatment and ongoing re-assessment to determine treatment effectiveness.

- develop comfort in interacting with patient and physically handling patient for evaluation and treatment interventions.

- begin to develop skills in treatment interventions.

- begin to develop skills in evaluation (as demonstrated in re-examinations).

- develop documentation skills that include appropriate content and terminology and a concise and specific assessment.

- begin to develop skills communicating with other health professionals.

- gain insight into their own clinical strengths and areas where they need support.

- begin to develop strategies for clinical success.

In light of the outcomes above, please summarize the student's current status in each of the following categories. In each instance, highlight an area of skill or strength and an area to focus for development.

EXAMINATION/EVALUATION: (i.e. appropriate selection of test \& measures, technique and accuracy of results, synthesis of information, etc.)

Strength

Focus for development

TREATMENT/INTERVENTION: (i.e., preparation for treatment, responsiveness to patient performance, development of a plan of care and level of independence in clinical decision-making, ability to provide rationale for planned intervention or tests, etc.)

Strength

Focus for development

DOCUMENTATION: (i.e., clarity, amount of feedback for documentation, appropriate terminology, timeliness, etc.)

Strength

Focus for development

COMMUNICATION: (i.e., communication with patients, family, Cls, fellow students and other health professionals.)

Strength

Focus for development

SAFETY: (i.e., awareness of surroundings, appropriate precautions, recognizing physiologic status of patient, guarding techniques and personal body mechanics.)

Strength

Focus for development

PROFESSIONAL BEHAVIORS: (i.e., personal appearance, punctuality, preparation, awareness of personal characteristics and behaviors during clinic and ability to take and give feedback.)

Strength

Focus for development 


\section{APPENDIX C}

\section{ICE III Student Performance Evaluation}

Throughout this experience, students will demonstrate progress in the ability to:

- demonstrate cultural competence by respecting individual differences as they relate to physical therapy practice, research and education.

- interpret the significance of developmental differences across the lifespan as they relate to physical therapy practice, research and education.

- develop clinical-decision making skills, including critical thinking, clinical reasoning and clinical judgment.

- use evidence from published literature to inform clinical-decision making and assist in the selection of appropriate treatment interventions.

- critically analyze assigned readings and other published literature.

- model the role of the physical therapist as educator in activities such as patient/client instruction, classroom presentations and/or in-service presentations that are appropriate to the unique characteristics of the learner(s).

- demonstrate safe and effective clinical practice that minimizes risk to the patient/client, physical therapist and others.

- determine the need to make an appropriate referral of a patient or client to another health care provider based on the results of a physical therapy examination and/or an abnormal response to treatment.

- participate effectively as a team member in a collaborative interdisciplinary environment.

In light of the above, please summarize the student's current status under the following categories. In each instance highlight an area of skill or strength and an area to focus for development.

EXAMINATION/EVALUATION:

- Performs a comprehensive physical therapy examination that is consistent with the guidelines in the Guide to Physical Therapist Practice.

- Identifies an appropriate physical therapy diagnosis based on the information obtained during the examination.

Strength Focus for Development

\section{TREATMENT/INTERVENTION:}

- Establishes a plan of care for assigned patients based on the results of the physical therapy examination and current evidence for best practice.

- Identifies appropriate goals or the level of improvement expected to be attained during this episode of care.

- Selects appropriate interventions based on the results of the physical therapy examination.

- Implements a plan of care that represents an appropriate depth and breadth of possible treatment options.

- Performs selected interventions in a safe and efficacious manner.

- Modifies interventions based on individual patient responses to treatment.

- Revises goals based on individual patient responses to treatment.

- Uses universal precautions in all clinic environments.

- Consults with appropriate health care providers.

Strength

Focus for Development

\section{DOCUMENTATION}

- Documents all aspects of physical therapy management including screening, examination, evaluation, plan of care, interventions, response to interventions, discharge planning and family conferences in a timely manner.

- Produces documentation of all aspects of patient management consistent with the requirements of the onsite clinic, regulatory agencies and third-party payers.

- Demonstrates professionally and technically correct written communication in all aspects of documentation.

- Submits documentation of patient care that is legible and concise in a timely manner. Strength Focus for Development 


\section{COMMUNICATION SKILLS}

- Communicates with patients with sensitivity to differences in race, creed color, gender, age, national or ethnic origin, sexual orientation, and disability or health status.

- Demonstrates professional and technically correct verbal and written communication with patients, family members, caregivers and other health professionals.

- Uses non-verbal communication that is appropriate for the intended audience.

- Interprets verbal and non-verbal communication of patients, caregivers and other health professionals correctly.

- Responds to verbal and non-verbal communication of patients, caregivers and other health professionals correctly.

- Evaluates the effectiveness of his/her own verbal and non-verbal communication.

- Modifies his/her own verbal and non-verbal communication to effectively convey intended messages.

- Presents on assigned patients during patient care conferences or cohort meetings in a concise manner using appropriate terminology.

- Consults (verbally or in writing) with other health care providers who are involved in the management of assigned patients.

- Communicates effectively and professionally with the $\mathrm{Cl}$ regarding patient management and issues as they occur throughout the clinical experience.

Focus for Development

\section{SAFETY}

- Provides a clean and safe work environment for patients and staff

- Adheres to the published safety policies and procedures for the onsite clinic.

- Demonstrates awareness of physical surroundings as well as the impact of other individuals whomay accompany the patient to clinic.

- Demonstrates knowledge of and adheres to appropriate precautions.

- Recognizes the physiologic status of the patient.

- Demonstrates proper guarding techniques.

Strength

- Uses good personal body mechanics.

\section{PROFESSIONAL BEHAVIORS}

- Demonstrates timely arrival to and departure from clinic and patient treatments.

- Is well-prepared for clinic and patient treatments.

- Remains actively engaged and eager to learn from both colleagues and $\mathrm{Cl}$.

- Demonstrates awareness of personal characteristics and behaviors during clinic.

- Demonstrates the ability to appropriately give and receive feedback from $\mathrm{Cl}$ and colleagues.

- Maintains a professional appearance in dress as described by the dress code in the On-Site Clinic Policies and Procedures Manual.

- Demonstrates behaviors consistent with the APTA Code of Ethics, Standards of Practice and Guide for Professional Conduct in clinical facilities.

- Develops personal learning objectives for the clinic experience in collaboration with the $\mathrm{Cl}$.

- Assesses his/her own performance and progress toward entry-level practice.

- Revises personal learning objectives for future clinical experience based on personal growth and development during this experience.

- Demonstrates self-reliance with problem-solving and actively collaborates with colleagues.

- Adheres to the guidelines for protecting patient confidentiality in compliance with the Clinic's HIPAA Policies and Procedures document 


\section{APPENDIX D}

\section{Student - CI Debriefing Summary ICE III 2012}

Cohort Collaboration: What did you find most valuable?

- Doing the first evaluation with a partner (2/8 groups)

- Developing other ideas and points of view for different treatment methods

- $\quad$ Sharing ideas and receiving feedback from peers ( $3 / 8$ groups)

- $\quad$ Being able to ask peers for help if needed

- Realistic collaboration as it is done in "real" clinics (3/8 groups)

- Helpful to learn about treating patients with diagnoses different than my own

- Having the $\mathrm{Cl}$ available as a consultant if needed

- $\quad$ Student lead meetings were valuable (2/8 groups)

- Helped model the transition from being classmates to being co-workers

- Leading discussions in cohort meetings helped develop professional language.

Cohort Collaboration: What did you find challenging about the collaborative model and what are some opportunities or ideas for cohorts in the future?

- Join or mix cohorts a few times to get new points of view (6/8 groups)

- Switch patients within cohorts occasionally (4/8 groups)

- Make sure that $\mathrm{Cl}$ facilitates discussion or helps get students back on track.

- Increase structure for having students lead discussions. Maybe the $\mathrm{Cl}$ could model the first one before students take over.

- Spend less time debriefing patient treatments toward end of semester and focus on more discussion topics.

- How about switching $\mathrm{Cls}$ for a day? It would be nice to have input from a different $\mathrm{Cl}$ with expertise in the same area. (2/8 groups)

What did you feel was most rewarding about the onsite clinic experience this fall?

- $\quad$ Ability to effect change and see improvement in patients' functional level

- $\quad$ Being able make recommendations to an orthotist or OT for consultation or ongoing care.

- Developing relationships with patients (3/8 groups)

- The physical environment was well-suited for learning.

- Working with patients without having to worry about financial constraints.

- Realizing areas in which we are making progress and areas in which we can still learn.

- Independently designing treatment plans for multiple patients.

What were the biggest challenges you faced in the onsite clinic this fall?

- Learning to work with patients and staff with different personalities.

- Discharging patients who did not want to leave.

- Working with patients who were non-compliant with their home exercise program.

- $\quad$ Documentation with a new EMR system.

- $\quad$ Working with patients who had self-referred to the clinic but were not appropriate for PT.

- Being put on the spot to do an impromptu evaluation.

- $\quad$ Seeing chronic patients who made minimal gains.

- Time management - having a new patient every hour!

- Reconciling stylistic differences between Cls when each one is certain that their way is the "best".

- $\quad$ Limited patient turnover.

- Revisiting or modifying goals for patients who were present for entire term.

How did the onsite clinic experience prepare you for your final two full-time clinical internships?

- Increased confidence in a clinical setting (5/8 groups)

- Improved communication skills with patients (2/8 groups)

- Increased number of treatment options and approaches

- Better perspective on goals and goal setting

- Increased comfort with exercise prescription/progression (2/8 groups) 


\section{Other comments:}

- $\quad$ Appreciated having the opportunity to meet one-on-one with Cls when needed. (2/8 groups)

- $\quad$ Liked being able to do a self-assessment of my own performance at mid-term and final and being able to discuss that with the $\mathrm{Cl}$.

- $\quad$ Having to write daily treatment plans for each patient ahead of time helped describe clinical reasoning and come up with back-up plans in case the first plan did not work.

- $\quad$ Liked being able to develop own style for evaluation and treatment within reason.

*Each idea/response was mentioned by a single group in the debriefing unless otherwise noted. 


\section{APPENDIX E}

Second-Year Third-Year Peer Mentoring Group Debriefing Summary 2012

Second-year students: What did you find most valuable about the shadowing experience?

- The opportunity for hands-on experience with patients on a limited basis. (19/36)

- Seeing the same patient several weeks and seeing how they progressed. $(11 / 36)$

- Working with the third-year students and seeing how comfortable they are in the clinic. (2/36)

- Observing in the onsite clinic cohort meetings to see the interaction between the $\mathrm{Cl}$ and the students. (3/36)

- $\quad$ Learning to communicate with patients, peers and Cls. (8/36)

- Working with several students to see differences in treatment and communication style. (3/36)

- The opportunity to work with both ortho and neuro patients (24/36)

- Observation in pediatrics was an entirely new experience (1/36)

Third-year students: What did you find most valuable about the shadowing experience?

- Having to explain clinical reasoning and rationale for interventions helped solidify the information in my mind. $(5 / 33)$

- Teaching students something that I feel somewhat comfortable doing. (4/33)

- Having the patients see me in a supervisory/authority role. (2/33)

- Getting the perspective of another student who does not know the patien. (6/33)

- $\quad$ Exchanging treatment ideas. (1/33)

- Being in a position of providing constructive feedback was hard but helped me grow. (7/33)

- Having second year students express confidence in my abilities as a therapist and as a teacher. (4/33)

- Becoming more confident in my ability to explain my thinking. (6/33)

\section{Second-year students: What did you find most challenging about the shadowing experience?}

- $\quad$ Not fully understanding the rationale behind some of the treatments I was observing. (7/36)

- $\quad$ Not having the same relationship with the patients as the third-year students do. (4/36)

- Documenting treatments that I was not entirely responsible for. (11/36).

- Documenting in a style that was different than I learned initially (paper vs. EMR). (2/36)

- $\quad$ Feeling put on the spot to answer questions in front of the patient. (2/36)

- Having to try a technique on the same patient more than once because it did not work the first time. $(1 / 36)$

- Sitting in on the cohort meetings when I did not know all of the patients that were being discussed. (2/36)

Third-year students: What did you find most challenging about mentoring second-year students?

- Having to teach when I am not comfortable with my own skills yet.(6/33)

- $\quad$ Having to provide feedback to someone who was doing at least as well as me. (4/33)

- $\quad$ Providing constructive feedback on documentation. (9/33)

- $\quad$ Giving control to someone else to treat my patient. (1/33)

- $\quad$ Finding new activities each week that the second year student could do with my patient. (6/33)

- Accepting constructive feedback from the second year student. (1/33)

- Providing a balance between letting the second year student try a skill and wanting to intervene and do it myself. (2/33)

NOTE: Third-year students $\mathrm{N}=33$, Second year students $\mathrm{N}=36$. Numbers following each comment indicate the frequency of the response. 


\title{
APPENDIX F
}

\section{Physical Therapy Satisfaction Questionnaire*}

\author{
*Adapted with permission of the American Physical Therapy Association from The Guide to Physical Therapist Practice $2^{\text {nd }}$ Ed. \\ You recently completed a course of physical therapy in the onsite clinic at the University of Puget Sound. Because we strive to \\ deliver the best possible care, we are interested in learning from our patients how we might improve our services. Please take a \\ few minutes to complete this questionnaire. \\ Please indicate the year and term in which you received care in the onsite clinic: \\ 2012 Fall \\ Spring 2013 \\ If you were seen in the clinic for treatment of a problem with your muscles or bones, please check the location of the problem. \\ (Check all that apply.) \\ Neck \\ Lower back \\ Shoulder \\ Elbow \\ Other (please indicate) \\ Hip \\ Knee \\ Foot/ankle \\ Wrist/hand \\ If you were seen in the clinic for treatment of mobility, balance or strength problems due to a neurological injury or condition, \\ please check the nature of the diagnosis. (Check all that apply.) \\ Stroke \\ Spinal Cord Injury \\ Cerebral Palsy \\ Other (please indicate) \\ Brain Injury \\ Parkinson's Disease \\ Multiple Sclerosis
}

Please rate your degree of satisfaction with each of the following statements by checking the appropriate box where 1 = strongly disagree and $\mathbf{5}=$ strongly agree.

\begin{tabular}{|l|l|l|l|l|l|}
\hline & & & & & \\
\hline My privacy was respected during my physical therapy care. & & & & & \\
\hline My student physical therapist was courteous. & & & & & \\
\hline $\begin{array}{l}\text { All other staff members (clinical instructors, office staff, aides, } \\
\text { etc.) were courteous. }\end{array}$ & & & & & \\
\hline $\begin{array}{l}\text { I was satisfied with the treatment provided by my student } \\
\text { physical therapist. }\end{array}$ & & & & & \\
\hline $\begin{array}{l}\text { I felt confident that my student physical therapist was } \\
\text { sufficiently knowledgeable about my condition. }\end{array}$ & & & & & \\
\hline $\begin{array}{l}\text { My student physical therapist consulted regularly with the } \\
\text { clinical instructor. }\end{array}$ & & & & & \\
\hline $\begin{array}{l}\text { The instructions that my student physical therapist gave me } \\
\text { were helpful. }\end{array}$ & & & & & \\
\hline $\begin{array}{l}\text { I was satisfied with the overall quality of my physical therapy } \\
\text { care in the onsite clinic. }\end{array}$ & & & & & \\
\hline
\end{tabular}

Please feel free to make any additional comments you may about your experience in the onsite clinic below. 